(C) John Schwenkler, 2012

This is the submitted version of an article that is forthcoming in Philosophy Compass. All citations should be to the published version.

\title{
Non-Observational Knowledge of Action
}

\author{
John Schwenkler, Department of Philosophy, Mount St. Mary’s University
}

\section{Introduction}

There seems to be something special about the knowledge of what one is intentionally doing. First, I have a kind of knowledge of $m y$ intentional actions that I seem not to be able to have of anyone else's: if I want to know what you are doing, I have to "look and see" (or perhaps ask you) in order to find out, whereas this seems not to be required for me to know that (say) I am presently sitting in my office and working on an article. Second, I appear to have a kind of knowledge of what I am doing intentionally that I seem not to have of my unintentional behaviors: to borrow a famous example from Elizabeth Anscombe (1963: 51), if in intentionally opening a window I happen to cast a spot of light on the wall, I will know about the windowopening in a way that I do not know about the casting of the spot of light. Call this twofold difference - between the knowledge of one's own intentional actions and the knowledge of the actions of other people, and the knowledge of one's own intentional actions and the knowledge of the things one does unintentionally - the Dual Asymmetry. It seems reasonable to hold that an adequate theory of action must explain why the knowledge of one's own actions is distinctive in these ways. ${ }^{1}$

To extend this analysis, here are three further ways we can characterize each asymmetry. First, the knowledge of one's actions is distinctive because it is usually necessary for an action to count as intentional: that is, except in extraordinary circumstances, if you do not know that you are doing something, you are not doing that thing intentionally. Second, the knowledge of one's own intentional actions is distinctive because it is instantaneous: one usually possesses this knowledge as soon as the action begins, and not a moment later. Third, the knowledge of one's own intentional actions is distinctive because it is exhaustive: that is, one usually knows one's actions under every description under which they are intentional. As my formulations suggest there seem to be counterexamples to each of these characterizations, but still it is important to 
explain why one generally knows one's own intentional actions in these special ways, ${ }^{2}$ whereas this is not true of the actions of other people or the things one is doing unintentionally. So how can we account for the fact that the knowledge of one's own intentional actions has these special characteristics, if not always then at least in general? ${ }^{3}$

This paper explores this question, surveying some of the recent attempts to answer it and noting some advantages and disadvantages of each. In order to keep the discussion manageable I will generally restrict my focus to work published after J. David Velleman's Practical Reflection (Velleman 1989). However, the main exception to this rule will be Anscombe's Intention, which remains the most influential and philosophically important treatment of these topics, and which I will refer to extensively. ${ }^{4}$ To make this survey manageable, I will use three taxonomies of accounts of the knowledge of action: one based on the source of that knowledge, a second based on its domain, and a third based on its special character. It should be noted that many accounts fall into more than one of these categories, and that the disadvantages of each can be a form of pressure to turn to the others. ${ }^{5}$

\section{2. "Special source" views}

Near the start of Intention, Anscombe suggests that a person always knows what he or she is intentionally doing "without observation", or in a way that is "not verified by the senses" (Anscombe 1963: 13, 54). This is a way of staking out a special source view, according to which an account of how we know what we are doing independently of perceiving it is central to explaining how this knowledge is distinctive. But is it true that we always know what we are doing without having to perceive it? And if so, then how do we know it instead?

Several recent versions of the special source approach center on the idea that the nonperceptual knowledge of what one is doing arises in some way from the agent's intention to act. For example, Velleman (1989) identifies intending to do something with expecting that one will do it, arguing that the natural human desire for self-understanding therefore motivates us to act on our intentions (since otherwise we would have false expectations of ourselves), and also not to act in ways we do not intend (since otherwise we would fail to understand what we do). Thus for Velleman, intention is a species of what Grice (1971) called "licensed wishful thinking": it is wishful, because prior to forming an expectation of what one will do any such expectation is no more likely to be true than many others; but it is licensed, because the desire for self- 
understanding makes the expectation of one's own behavior a kind of self-fulfilling prophecy. By contrast, Kieran Setiya $(2007,2008)$ rejects Velleman's outright identification of intention with belief but still holds that intending to do something involves believing that one will do it, and that since we usually know how to do the things we intend to do and know that we possess this know-how, when a person does something intentionally the accompanying belief that she is doing it will usually be justified. And Sarah Paul (2009a) has recently proposed a different sort of intention-based view, according to which the knowledge of one's actions is based on a (likely unconscious) inference from the knowledge of one's intentions, plus other knowledge that justifies this transition. For Paul, this latter knowledge involves the knowledge of one's abilities, one's general tendency to do the things one intends, and the favorability of the surrounding circumstances to success in the relevant behavior. This account differs from Velleman's and Setiya's in denying that intention itself involves belief, but all three share the conviction that intentional action is generally accompanied by a justified belief that one is acting in the way in question. ${ }^{6}$ In cases where one is acting in this way, they suppose, this justified belief amounts to non-observational knowledge

A very general worry for all these "special source" accounts lies in the evident possibility of accidentally failing to act as one intends to. ${ }^{7}$ In a case where this possibility is present but the agent lacks any observational awareness of her action, how can she know whether she is doing what she intends? Some theorists (e.g. Velleman 1989: 19-20; Newstead 2006: 196-200) respond by noting that our ordinary conception of knowledge does not require the absence of possible doubt, and so one can know what one is doing without being able to rule the possibility of error out completely. But even if knowledge can be uncertain the knower must have at least some measure of reliability in the relevant circumstances, and so it is hard to see how this response can work in cases where failure is quite likely, e.g. ones involving especially hard-to-perform actions, challenging conditions, extremely weak-willed agents who tend not to follow through on their intentions, and so on (cf. Velleman 2007: 202-04; Grünbaum 2009: 60-61; Schwenkler 2011: 141-43). If we suppose that there is no non-observational knowledge of one's actions in cases like these, then these "special source" accounts will become versions of the "special domain" view discussed below, and will be subject to the difficulties surveyed there.

Another way philosophers have tried to address this worry is by appeal to what linguists call the "broadness" of the progressive forms of action-verbs, which allows considerable 
flexibility in what a person can truly be said to be doing (e.g. Falvey 2000; Thompson 2008: ch. 8, 2011; Paul 2009a; Haddock 2011): for example I can spend many months writing an article even if I never complete it, and can be said to be writing it even when I am not making any progress at all. But most of those who make this sort of appeal tend to acknowledge that our ordinary intuitions about what it takes to "be doing" certain things aren't sufficiently liberal for it to work in all the difficult cases. More precisely, this sort of broadness seems to characterize only what linguists call telic verbs, or concepts that represent actions as aiming at some sort of completion, whereas the present progressive forms of atelic action concepts are not so broad (see Galton 1984): thus e.g. I may be said to be walking to a certain building (a telic characterization) even if I am heading in the wrong direction altogether, but I count as walking toward it (an atelic characterization) only if the distance between me and it is presently decreasing. As Anscombe says (1963: 52), the idea that "I really 'do' in the intentional sense whatever I think I am doing" is a "false avenue of escape" from the intuitive difficulties with the idea that we know our actions without observation; for it simply must be possible to fail to be doing what one intends.

\section{3. "Special domain" views}

Given the difficulties in explaining how the knowledge of one's actions always arises from a non-perceptual source, those who adopt the special source approach seem forced into a special domain view, according to which the range of actions (or aspects of actions) that are known non-observationally is restricted in some way. One way to do this is to note that an agent will always have non-perceptual access to some action-related facts even if she does not know in this way all the things she is intentionally doing: at the very least, a person attempting to engage in a difficult action knows what she intends (Donnellan 1963) or is trying (O'Shaughnessy 2003) to do, and perhaps also knows her bodily movements thanks to proprioception and kinesthetic feedback, which several philosophers (e.g. Anscombe 1962, 1963: 13-15; Gallagher 2003; McDowell 2011) have held are not forms of sense-perception. ${ }^{8}$ Similarly, some have proposed that the scope of non-observational knowledge may extend to all basic actions, where these are things a person can do without doing any distinct things in order to do them (for some such accounts, see Danto 1963; O’Brien 2003: 381, 2007: 160-61; Hossack 2003; Peacocke 2003, 2008a, 2008b: ch. 6; Pickard 2004; Grünbaum 2011). If things like these can be secured against 
the threat of likely failure, then they seem able to provide at least a core domain of nonobservational knowledge of what one does.

But a problem here is that even bodily movements and basic actions are not entirely immune to failure: for example I may try to move my arm when in fact it is tied down (and perhaps anesthetized), or try to turn on a light when the bulb is burnt out. And even if in general our beliefs about our bodily movements and basic actions are reliably true, it is possible for there to be circumstances where this is not so, e.g. if a person has lost control of her limbs, or is in a house where it has been several years since any of the light bulbs have been changed, and so on. So the main difficulty for special source views remains, albeit with a smaller number of problem cases.

Another way to deal with these difficulties is to restrict the domain of non-observational knowledge to actions that can be performed reliably in the relevant circumstances (e.g. Velleman 2007: 202-04; and cf. Velleman 1989: 26, Falvey 2000: 36-37, 39-40). This might suffice to address the difficulties facing special source views, but this response runs the risk of becoming trivial unless the relevant class of actions can be appropriately delineated, lest we should be able to say no more than, "Actions are known without observation ... except when they are not". Perhaps, though, this is an obstacle that can be overcome. ${ }^{9}$

However, the main difficulty for all these special domain views is the intuition that they concede too much. To see this, imagine that you are visiting an unfamiliar campus, and you and I have planned to meet for coffee. You decide to find me in my office, and set out on your own, optimistically believing that you are heading the right way. Even if you are, in fact, walking toward my office, it seems possible that you do not know that you are, assuming that the campus is large and very unfamiliar to you: for your success will be too much a matter of luck. But then you see me coming out the door of the building you are heading toward, and now you know: you are indeed walking toward my office. This knowledge seems to be perception-based, and so a special domain view will decline to count it as non-observational. But is it plausible that your knowledge that you are walking toward my office is the very same sort of knowledge as someone else's knowledge of this fact, or as your knowledge that (say) you are walking along the path where Famous Philosopher X took her afternoon walk each day while she taught at this university? (Perhaps there is a plaque on the walkway that says this.) That would be a very 
unintuitive verdict. Yet if we identify the specialness of the knowledge of one's actions just with its being independent of sense perception, there seems to be no alternative.

A similar problem arises for one further view worth noting here, though it is not explicitly meant to restrict the scope of non-observational knowledge just to a sub-domain of intentional action in general. Richard Moran (2004) has argued that the knowledge of what one is intentionally doing is not observational because it cannot be, as perceptual observation of a person's behavior can never reveal all of the descriptions under which that behavior is intentional. (For example: suppose that a few minutes ago you looked in to see me staring out the window with my hands behind my head. Would this have shown you that I was writing a paper, let alone a paper on the knowledge of action? Yet I knew this all along.) But Moran still allows that the knowledge of one's actions might be dependent on the perception of them in some way: thus in the above example it may be only because you perceive it that you know you are walking toward my office, even if perception alone wouldn't reveal that you were going to meet me for a cup of coffee. This preserves a kind of first-person/third-person asymmetry and a distinction between intended and unintended actions, but it lacks the scope of some more ambitious views, and still faces the difficulty identified above of explaining how your knowledge that you are walking toward my office is different from the knowledge you might have of various things you are doing unintentionally. So perhaps we should try a different approach.

\section{4. "Special character" views}

The argument of Section 3 suggests that one problem with special source views is that independence from perception may not be necessary for the knowledge of one's intentional actions to be a special sort of knowledge: your knowledge that you are walking toward my office, even if perception-based, is still a different sort of knowledge than your knowledge that you are walking on a path once frequented by Famous Philosopher X. But another difficulty with the special source approach is that independence from perception seems not to be sufficient for this epistemic distinctiveness, either. To see this, imagine someone with a special sort of "actionreading" power in virtue of which she can tell without looking what any given person is doing, at the very instant at which the person begins doing it. This knowledge would be non-perceptual, yet presumably something will be missing from the action-reader's knowledge of the actions of others that makes it different from "the knowledge a man has of his intentional actions" (see 
Anscombe 1963: 50). The knowledge of what one is intentionally doing seems to involve something more than a special access to the behavior of a person who happens to be oneself, and so accounting for what is distinctive about this knowledge requires more than explaining how it arises from a non-perceptual source.

In light of this sort of worry, "special character" accounts attempt to understand the distinctiveness of the knowledge of action in terms of the nature of the knowledge itself. Here we can take a hint from Anscombe, who emphasizes what she calls the "practical" character of the knowledge of one's intentional actions, or the fact that such knowledge is "the cause of what it understands" rather than being, like ordinary "speculative" knowledge, "derived from the objects known" (Anscombe 1963: 87). ${ }^{10}$ She illuminates this idea with a famous contrast between two lists: one carried by a man who is going around town buying the things that are on it, and another drawn up by a detective who has been tracking him (see Anscombe 1963: 56). The interest of the example lies in the differing ways the two lists relate to the facts they represent. The detective's list is supposed to report what the man in fact buys; thus if it lists something that the man does not purchase, then the detective has done something wrong. The shopper's own list, on the other hand, functions not to describe but rather to direct his purchases, and so he is accountable to it, not it to him: anything on the list that is not among his purchases shows that the shopper is in the wrong, rather than the list (unless of course he had a good reason for going against the directions). By contrast, the detective is supposed to derive the contents of his list from the things the shopper buys, and so the things he writes are accountable to how things are in the world.

More recently, a similar idea has been developed by Moran, who argues for a parallel between the kinds of rational agency involved in belief and intentional action. According to Moran, it is a part of rational agency that the agent "can and must answer the question of his belief or action by reflection on the reasons in favor of this belief or action"; for if this were not so then the agent must "take the course of his belief or his intentional action to be up to something other than his sense of the best reasons, and if he thinks that, then there's no point in his deliberating about what to do" (Moran 2001: 127). Thus Moran holds that the knowledge of what one is intentionally doing is transparent to reflection on the question what to do, just as one knows what one believes simply by considering what is true: each is a species of "spontaneous" knowledge that is a product of rational agency, rather than "speculative" knowledge that reflects an independent fact. ${ }^{11}$ 
I think there is a lot to be said for this general approach. But how is this concept of practical knowledge supposed to help us deal with cases where "a man is simply not doing what he says" (Anscombe 1963: 57), or is in a situation in which, excluding whatever he observes of his action, he seems not to know that this is not the case? (For contra Moran, one important difference between action and belief is that failure in the execution of an intended action is quite unlike the failure to believe what one judges to be true, in being a common occurrence that does not always represent a failure of rationality.) Anscombe's response is to draw a parallel with the shopping list, saying that when one fails to do as one intends, "the mistake is not one of judgment but of performance" (1963: 57): that is, if a person judges herself to be doing something which she intends to do but is not in fact doing, there is no error in her judgment, but only in her failure to actualize its truth-conditions. ${ }^{12}$ And it is hard to know what to make of this suggestion. If one can know in the "practical" sense that one is acting in a way that one is not acting, then "practical knowledge" does not appear to be any kind of knowledge at all.

While this last aspect of Anscombe's view has not won many supporters, subsequent theorists have built on her account of practical knowledge in several ways. For example, Moran (2004) rejects the claim that the knowledge of one's action can ever be non-factive, but claims that such knowledge is "the cause of what it understands" insofar as actions that an agent does not know about cannot be intentional. ${ }^{13}$ For Moran and others (e.g. Hursthouse 2000; Newstead 2006, 2009; Haddock 2010) this constitutes a kind of "formal causality", insofar as the knowledge of an intentional action is that which makes the action the kind of thing it is. One significant difficulty facing this sort of view is the apparent possibility of intentional actions that are not known by their agents, as for example when a man intentionally makes a stack of ten legible carbon copies without belief in his success (see Davidson 1980: 92), but it may be possible to modify the thesis to account for such difficulties (for some attempts see Setiya 2008, 2009, 2011; and cf. Paul 2009b). Without question (and see Gibbons 2010 for a further exploration of some related ideas), the metaphysical "non-independence" of intentional actions from agents' knowledge of them is an important aspect of what makes that knowledge epistemically distinctive.

However, more radical versions of the special character approach suggest that since the knowledge of one's intentional actions is a form of practical knowledge, there is no need to ground it in any special source at all. For example, Johannes Roessler (2003) has argued that the 
special character of the knowledge of one's actions lies in the fact that an agent uses perception to answer "practical questions" rather than "theoretical" ones: that is, for an agent the question "What am I doing?" does not concern a bare matter of fact, but rather is always in the service of enabling her behavior to unfold as she intends it to. Roessler seems to follow Anscombe, though, in holding that this knowledge does not represent how things are at all: on his account, what distinguishes the awareness of one's intentional actions from the awareness of other things lies in the distinctive "direction of fit" that results from its being used in the service of action, and not arising from merely speculative fact-gathering.

Here is a different way to develop a special character view. In an influential paper, Harry Frankfurt criticizes the traditional causal theory of action for being unable to explain why agents are necessarily "in touch" with their purposive behaviors, arguing that what makes an action intentional is not its antecedent causes, but rather the fact that the agent stands ready "to bring about compensatory adjustments tends to ensure that the behaviour is accomplished" (Frankfurt 1978/1997: 44, 48). If this is right, then the knowledge of what one is doing seems to be an essential part of intentional action itself: for unless has this knowledge, one cannot make the adjustments that might be necessary to keep one's behavior on course. It will not matter, however, if this agentive self-knowledge is based on perception or not; what distinguishes it is the causal role it plays in the process of self-guidance.

If we follow Frankfurt, then we seem to have isolated an important sense in which the knowledge of one's intentional actions is "the cause of what it understands": approximately at least, if I mean to be doing something, then so long as I know that I am doing it I will keep acting as I am; but if I come to see that my behavior has gone off course I will try to adjust it appropriately. ${ }^{14}$ On this account, the causal role of practical knowledge is to be understood efficiently, and not merely formally as in accounts like Moran's: the suggestion is that it is because a person knows what she is doing that she acts as she does, and can keep her action on track; had this knowledge been absent, her behavior would have unfolded quite differently. ${ }^{15}$ Thus there is a sense in which the knowledge of one's action is a proper part of the action itself, and not a mere accompaniment to it; it is in acting that one knows what one is doing, because the ways one acts are guided by the very knowledge one has of them. ${ }^{16}$

As I noted above, this sort of special character account rejects the idea that the knowledge of one's intentional actions must be secured via a special non-perceptual source, focusing instead 
on the role of such knowledge in agentive self-guidance. Does that leave it unable to explain the Dual Asymmetry? Recall the three features identified above. This special character view seems able to explain why knowledge of what one is doing is (at least usually) necessary for intentional action, since it postulates a link between such self-knowledge and the process of self-guidance that distinguishes intentional behaviors from unintentional ones. (In extraordinary cases you might be forced to act just in the belief that you are doing what you intend to, but in general it will be better to know.) It also explains why an agent will usually have such knowledge immediately upon beginning to act, and will not have to "look and see" to gain it: for if intentional action itself is a process of dynamic self-guidance, then the agent will usually keep track of her behaviors right from the beginning, and so no further looking will be required to see how things are going. Finally, it explains why this knowledge exhausts the descriptions under which an action is intentional: for it will be precisely under those descriptions that the agent is disposed to monitor her behavior and adjust it as necessary to keep things on course. And it seems clear that none of these things are true of the way we relate to our unintentional actions, or to the intentional and unintentional behaviors of other people (even ones we might somehow know non-perceptually).

\section{Conclusion}

My purpose in this paper has been to propose a way of conceiving recent debates in the epistemology of action that will help to orient those who are new to them and perhaps provide some guidance to those of us who are caught up in their midst. The space of options surveyed here is far from exhaustive, and I regret having had to take some liberties in leaving certain issues out and forcing such complex views into these somewhat rigid categories. A great deal of work remains to be done in addressing these questions and relating them to issues in the study of self-knowledge, the consciousness of agency, the metaphysics of human action, moral psychology and the nature of moral responsibility, and so on. If the recent growth of interest in the topic of non-observational knowledge is any indicator of its philosophical importance, there is every reason to believe that further pursuit of these issues will be worth the while. ${ }^{17}$

\section{References}


Anscombe, G.E.M. 1962. On sensations of position. Analysis 22/3: 55-58. 1963. Intention, $2^{\text {nd }}$ ed. Repr. 2000, Cambridge: Harvard University Press.

Aquinas, T. 1983. Treatise on Happiness, trans. J.A. Oesterle. Notre Dame: University of Notre Dame Press.

Bermúdez, J.L. 1998. The Paradox of Self-Consciousness. Cambridge: The MIT Press.

Danto, A.C. 1963. What we can do. Journal of Philosophy 60/15: 435-45.

Davidson, D. 1980. Intending. D. Davidson, Essays on Actions and Events, pp. 85-102. New York: Oxford University Press.

Donnellan, K. 1963. Knowing what I am doing. Journal of Philosophy 60/14: 401-09.

Dunn, R. 1998. Knowing what I'm about to do without evidence. International Journal of Philosophical Studies 6/2: 231-52.

Falvey, K. 2000. Knowledge in intention. Philosophical Studies 99/1: 21-44.

Ford, A. 2011. Action and generality. A. Ford, J. Hornsby, and F. Stoutland (eds.), Essays on Anscombe's Intention, pp. 76-104. Cambridge: Harvard University Press.

Frankfurt, H. 1978/1997. The problem of action. A. Mele (ed.), The Philosophy of Action, pp. 42-52. New York: Oxford University Press.

Gallagher, S. 2003. Bodily self-awareness and object perception. Theoria et Historia Scientiarum 7/1: 53-68.

Galton, A. 1984. The Logic of Aspect: An Axiomatic Approach. Oxford: Clarendon Press.

Gibbons, J. 2010. Seeing what you're doing. T. Szabo Gendler and J. Hawthorne (eds.), Oxford studies in epistemology, vol. 3, pp. 63-85. New York: Oxford University Press.

Grice, H.P. 1971. Intention and uncertainty. Proceedings of the British Academy 57: 263-79.

Grünbaum, T. 2009. Anscombe and practical knowledge of what is happening. Grazer Philosophische Studien 78: 41-67.

- 2011. Non-inferential knowledge of action. Philosophical Explorations 14/2: 153-67.

Haddock, A. 2010. Knowledge of action. D. Pritchard, A. Millar, and A. Haddock, The Nature and Value of Knowledge, pp. 241-60. New York: Oxford University Press.

- 2011. The knowledge that a man has of his intentional actions. A. Ford, J. Hornsby, and F. Stoutland (eds.), Essays on Anscombe's Intention, pp. 147-169. Cambridge: Harvard University Press.

Hampshire, S. 1959. Thought and Action. London: Chatto and Windus. 
Hossack, K. 2003. Consciousness in act and action. Phenomenology and the Cognitive Sciences 2/3: 187-203.

Hursthouse, R. 2000. Intention. R. Teichmann (ed.), Logic, Cause \& Action, pp. 83-105. New York: Cambridge University Press.

Jarvis, J. 1959. Review of Intention, by G.E.M. Anscombe. Journal of Philosophy 56/1: 31-41. Martin, M.G.F. 1995. Bodily awareness: a sense of ownership. J. L. Bermúdez, A. Marcel, and N. Eilan (eds.), The Body and the Self, pp. 267-89. Cambridge: The MIT Press. . 1997. Self-observation. European Journal of Philosophy 5/2: 119-140.

McDowell, J. 2010. What is the content of an intention in action? Ratio 23/4: 415-32. . 2011. Anscombe on bodily self-knowledge. A. Ford, J. Hornsby, and F. Stoutland (eds.), Essays on Anscombe's Intention, pp. 128-146. Cambridge: Harvard University Press.

Moran, R. 2001. Authority and Estrangement: An Essay on Self-Knowledge. Princeton: Princeton University Press.

—. 2004. Anscombe on "practical knowledge". J. Hyman and H. Steward (eds.), Agency and Action, pp. 43-68. New York: Cambridge University Press.

Newstead, A. 2006. Knowledge by intention? On the possibility of agent's knowledge. S.S. Hetherington (ed.), Aspects of Knowing, pp. 183-202. Oxford: Elsevier Ltd.

- 2009. Interpreting Anscombe's Intention 32ff. Journal of Philosophical Research 34: 157-76.

O'Brien, L. 2003. Knowing one's own actions. J. Roessler and N. Eilan (eds.), Agency and SelfAwareness, pp. 358-82. New York: Oxford University Press.

- Self-Knowing Agents. New York: Oxford University Press.

O'Shaughnessy, B. 1963. Observation and the will. Journal of Philosophy 60/14: 367-92. 1995. Proprioception and the body image. J. L. Bermúdez, A. Marcel, and N. Eilan (eds.), The Body and the Self, pp. 175-204. Cambridge: The MIT Press.

- 2003. The epistemology of physical action. J. Roessler and N. Eilan (eds.), Agency and Self-Awareness, pp. 345-57. New York: Oxford University Press.

Paul, S.K. 2009a. How we know what we're doing. Philosophers' Imprint 9/11: 1-24. . 2009b. Intention, belief, and wishful thinking: Setiya on "practical knowledge". Ethics 119/3: 546-57. 
Peacocke, C. 2003. Action: awareness, ownership, and knowledge. J. Roessler and N. Eilan (eds.), Agency and Self-Awareness, pp. 94-110. New York: Oxford University Press.

- 2008a. Mental action and self-awareness (II): epistemology. L. O'Brien and M.

Soteriou (eds.), Mental Action, pp. 192-214. New York: Oxford University Press.

- 2008b. Truly Understood. New York: Oxford University Press.

Pickard, H. 2004. Knowledge of action without observation. Proceedings of the Aristotelian

Society 104/3: 203-28.

Rödl, S. 2007. Self-Consciousness. Cambridge: Harvard University Press.

Roessler, J. 2003. Intentional action and self-awareness. J. Roessler and N. Eilan (eds.), Agency

and Self-Awareness, pp. 383-405. New York: Oxford University Press.

- 2010. Agents' knowledge. T. O'Connor and C. Sandis (eds.), The Blackwell

Companion to the Philosophy of Action, pp. 236-243. Oxford: Basil Blackwell.

Schwenkler, J. 2011. Perception and practical knowledge. Philosophical Explorations 14/2: 13752.

. The objects of bodily awareness. Philosophical Studies, forthcoming.

Setiya, K. 2007. Reasons without Rationalism. Princeton: Princeton University Press.

- 2008. Practical knowledge. Ethics 118/3: 388-409.

2009. Practical knowledge revisited. Ethics 120/1: 128-37.

. 2011. Knowledge of intention. A. Ford, J. Hornsby, and F. Stoutland (eds.), Essays on Anscombe's Intention, pp. 170-97. Cambridge: Harvard University Press.

Teichmann, R. 2008. The Philosophy of Elizabeth Anscombe. New York: Oxford University Press.

Thompson, M. 2008. Life and Action. Cambridge: Harvard University Press.

- 2011. Anscombe's Intention and practical knowledge. A. Ford, J. Hornsby, and F.

Stoutland (eds.), Essays on Anscombe's Intention, pp. 198-210. Cambridge: Harvard

University Press.

Velleman, J.D. 1989. Practical Reflection. Repr. 2007, Stanford: CSLI Publications. 2007. What good is a will? A. Leist (ed.), Action in Context, pp. 193-215. Berlin:

Walter de Gruyter.

Wilson, G. 2000. Proximate practical foresight. Philosophical Studies 99/1: 3-19. 


\section{Notes}

${ }^{1}$ In what follows I will often use "knowledge of action" as shorthand for "knowledge of one's own intentional actions", though not where certain contrasts need to be drawn explicitly.

2 That is, they may be instances of what Ford (2011) calls "essential generality".

${ }^{3}$ Note that knowledge of what one is presently doing is different from "practical foresight", or a person's knowledge of what she will be doing at some point in the future. My concern here is only with the former issue. For some recent discussions of practical foresight, see Velleman (1989: ch. 8), Dunn (1998), and Wilson (2000).

${ }^{4}$ Another seminal account of this idea can be found in Hampshire (1959). For discussion of the earlier literature on this issue, see Velleman (1989: ch. 1), especially the works referenced in the footnotes on pp. 18-19.

${ }^{5}$ For another recent review of this literature, see Roessler (2010).

${ }^{6}$ This is not to minimize the differences between these accounts: indeed, Setiya (2011) criticizes inferential views at length, arguing that "it is by knowing what we are doing, or what we are going to do, that we know what we intend", rather than the other way around (p. 177). That is, unlike Paul Setiya holds that when one is doing something intentionally her belief that she is doing it is not based on any prior knowledge of her intentions; rather it is a form of justified but "groundless" knowledge, similar to our knowledge of what one believes.

${ }^{7}$ For another objection to accounts like these, see Gibbons (2010).

${ }^{8}$ This last claim is controversial, however: see O'Shaughnessy (1995); Martin (1995, 1997); Bermúdez (1998); Pickard (2004: 212-18), and Schwenkler (forthcoming).

${ }^{9}$ Setiya (2011) attempts to address this sort of challenge by proposing that agents necessarily have a general capacity for non-observational knowledge of their actions, even if this capacity cannot always be exercised.

${ }^{10}$ Anscombe credits Aquinas' Summa Theologiae IaIIae, q. 3, a. 5 (Aquinas 1983: 34) as the inspiration for this doctrine.

11 There is a similar idea in Rödl (2007: ch. 2).

12 This interpretation of Anscombe is mildly controversial, but widespread enough that the questions about it need not detain us here. For readings of Anscombe along these lines, see Jarvis (1959), Velleman (1989: 102-105), Moran (2004), Setiya (2008), Teichmann (2008: 22-26), Newstead (2009), Grünbaum (2009), and McDowell (2010).

${ }^{13}$ As Anscombe puts it, the knowledge of an action causes what it understands insofar as "without it [viz. the knowledge] what happens does not come under the description-execution of intentions - whose characteristics we have been investigating" (1963: 88).

${ }^{14}$ Of course these counterfactuals need to be worked out very carefully; I do this in forthcoming work.

${ }^{15}$ Perhaps it will be objected that my knowledge of what I am doing right now can only affect future actions, not present ones. But it is not clear that this is the only way we can think about causation: e.g. it seems to be because my chair is currently underneath me that I am 
currently above the floor. Of course there is much more to say about this, which I cannot get into here.

${ }^{16}$ For a somewhat different development of this idea, see Schwenkler (2011), where I appeal to O'Shaughnessy's (1963) distinction between "observing" and "perceiving" to explain how the knowledge of one's actions is distinctive.

17 Thanks to Tim Bayne, Thane Naberhaus, Beri Marušić, and an anonymous referee for helpful feedback, and to Adrian Haddock and Johannes Roessler for assistance in tracking down some resources. 